\title{
Effects of Manual Therapy on Upper Extremity Pain after Breast Cancer Surgery: A Systematic Review and Meta-analysis
}

\author{
Sangyeop Kimª ${ }^{a}$, Hyun-Joong Kim ${ }^{b}(\mathbb{D}$ \\ aDepartment of Physical Therapy, Gwangju Health University, Gwangju, Republic of Korea \\ ${ }^{\text {b } C a n c e r ~ C e n t e r ~ C h u n g h a l i n ~ H o s p i t a l, ~ G w a n g j u, ~ R e p u b l i c ~ o f ~ K o r e a ~}$
}

\begin{abstract}
Objective: The most common type of cancer in women is breast cancer, and pain in the upper extremity and trunk is a discomfort experienced by more than half. Based on the evidence that manual therapy is effective for pain control in postoperative rehabilitation, this study aims to analyze the effects of manual therapy on upper extremity pain and function in patients after breast cancer surgery.
\end{abstract}

Design: A systematic review and meta-analysis.

Methods: We searched MEDLINE, Embase, PEDro, and CINAHL databases until August 2021. We included randomized controlled trial evaluating pain and function in patients after breast cancer surgery. Qualitative analysis was performed using Cochrane's risk of bias tool, and quantitative analysis was performed using RevMan 5.4 to analyze post-intervention outcomes.

Results: Four randomized controlled trials were selected to evaluate the effects of upper extremity pain and function in 133 patients who underwent manual therapy after breast cancer surgery. In the results of qualitative and quantitative analysis, the experimental group treated with manual therapy showed a significant improvement in pain compared to the control group (-0.62; $95 \%$ confidence interval (CI) -0.97 to -0.27$)$. However, there was no significant improvement in upper extremity function (-0.09; $95 \%$ CI -0.43 to 0.25 ).

Conclusions: Current evidence shows that manual therapy is effective for pain control in patients who complain of upper extremity pain after breast cancer surgery.

Key Words: Breast cancer, Manual therapy, Postoperative pain, Cancer pain, Physical therapy

\begin{abstract}
서론
유방암 수술 후 재활에서 다양한 방법들이 제안되지만 도 수치료(manual therapy)는 통증 조절뿐만 아니라 암과 관련 된 피로에 긍정적인 개선을 보인 것으로 정신생리학적 요소 에 영향을 미친다고 보고되었다[5]. 도수치료는 근육 마사 지, 근막 이완(myofascial release), 통증유발점 치료(trigger pointtherapy), 도수 견인(manual traction), 연부조직 가동술 (soft tissue mobilization), 관절가동술(joint mobilization)과 같이 다양한 형태로 제공될 수 있다[6].도수치료를 통한 통 증의 조절과 기능의 향상은 근육과 근막에서의 섬유성 조직 (fibrotic tissue)의 이완을 통해 해결된다[7].
\end{abstract}

유방암 수술 후 통증 및 기능의 향상을 위한 연구들에 서는 물리치료의 일환으로 능동 운동(active exercise), 근 력운동(strength exercise)과 결합된 프로그램들이 증상의 개선을 보였다[8]. 하지만, 현재까지 유방암 수술 후 도수 치료의 이점은 명확하게 알려진 바 없다[9]. 정리해 보면, 유방암 수술 후 여성들에게서 팔과 체간에 불편감을 미친 다는 점과 이로 인해 만성통증이 야기되어 도수치료를 통 한 효과검증을 위한 연구들에서 현재까지 논란의 여지가 있다는 것이다 $[10,11]$.

따라서, 본 체계적 고찰 및메타분석에서는 유방암 수술 후 여성들의 팔 통증에 대한 도수치료의 효과를 질적 (qualitative) 및 양적(quantitative) 분석을 통해 임상에서

Received: Sep 7, 2021 Revised: Sep 10, 2021 Accepted: Sep 14, 2021

Corresponding author: Hyun-Joong Kim (ORCID https://orcid.org/0000-0001-6538-3872)

Cancer Center Chunghalin Hospital, 61, Gaegeum-gil, Seo-gu, Gwangju, Republic of Korea [62070]

Tel: + 82-10-8005-1460, Fax: +82-62-958-7786, E-mail: doong18324@gmail.com

This is an Open-Access article distributed under the terms of the Creative Commons Attribution Non-Commercial License (http://creativecommons.org/licenses/ by-nc/4.0) which permits unrestricted non-commercial use, distribution, and reproduction in any medium, provided the original work is properly cited.

Copyright @ 2021 Korean Academy of Physical Therapy Rehabilitation Science 
의 도수치료 필요성에 대해 제언하고자 한다.

\section{연구 방법}

\section{연구설계}

본 연구는 유방암 수술 후 도수치료 효과를 통합하고 분석하기 위한 체계적 고찰 및 메타분석연구이다. 체계적 고찰을 진행하기 위해 Preferred Reporting Items for Systematic Reviews and Meta-analysis(PRISMA)의 지 침에 따라 진행하였다.

\section{자료의 선정 및 배제기준}

핵심 질문전략으로 PICOSD(Participants [P], Intervention [I], Comparison [C], Outcomes [O], Study Design [SD]) 에 따라 데이터베이스 검색 후 문헌을 검토하였다.

\section{선정기준}

유방암 수술 후 여성들 $(\mathrm{P})$ 에게 도수치료(I)를 제공한 연구들을 포함한다. 비교대상 $(\mathrm{C})$ 은 도수치료의 효과검증 을 위함으로 제한을 두지 않았다. 결과 $(\mathrm{O})$ 변수들은 팔 통 증과 기능이며, 연구 유형(SD)은 최신 연구동향을 반영하기 위해 10 년 이내의 국외의 무작위 대조 시험(randomized controlled trial [RCT])만 포함하였다.

\section{배제기준}

도수치료를 시행한 RCT에서 유방암 수술 후 환자를 대상으로 하지 않은 연구, 대조군으로 도수치료가 포함된 연구들은 고찰에서 제외하였다.

\section{문헌 검색 및 선정}

\section{문헌 검색전략}

문헌검색은 2021년 08월에 검색 및 수집되어 메타분석 경험이 있는 연구자 2 인에 의해 각각 독립적으로 자료를 탐색하였다. 검색식은 $\mathrm{P}, \mathrm{I}, \mathrm{SD}$ 를 나타내는 용어를 병합 하여 구성하였다.

사전 식별된 키워드(pre-identified keywords)는 (Breast Cancer AND Manual therapyAND [Pain OR Shoulder function]AND Randomized Controlled Trial)와 색인용어 (index term)가 포함된 데이터베이스인 Medical Literature Analysis and Retrieval System Online (MEDLINE), Excerpta Medica Database (Embase), Cumulative Index of Nursing and Allied Health Literature (CINAHL), Physiotherapy Evidence Database (PEDro)를 포함하였다.

\section{연구 선정 및 자료의 추출}

데이터베이스를 통해 검색된 연구들은 참고문헌 관리 소프트웨어(EndNote X9, Thomson Reuters, USA)를 이 용하여 중복된 연구들을 제거하였다. 먼저 제목과 초록을 통해 스크리닝(screening) 후 선정기준에 따라 논문들의 원문을 검토하였다. 이러한 과정에서는 연구자들이 최종 적인 추출을 위해 합의하는 하는 과정을 밟았다. 추출과 정에서 일반적 특성, 중재의 특성, 연구결과를 추출하였 다. 혹여 자료가 일치하지 않을 경우에는 원문을 함께 검 토하여 최종적으로 선정하였다.

\section{질평가}

RCT의 경우, Cochrane Bias Method Group에 의해 개 발된 7개 항목 Cochrane's risk of bias(RoB)를 이용하였 다. 연구의 질 평가를 위해서 연구자 2 인이 비뚤림의 위험 을 낮음(+), 높음(-), 불확실(?)로 평가 후 일치되지 않은 문 항들을 함께 원문을 재검토하는 과정을 통해 합의하였다.

\section{자료 통합 전략}

자료의 통합은 검토 소프트웨어(RevMan 5.4, The Cochrane Collaboration, England)를 통해 분석하였다. 분석이 가능한 동일 변수가 있거나 사전 및 중재 후 검사 에서 양적변수가 있을 때 메타분석에 포함시켜 수행하였 다. 메타분석에 포함시키기 위해서는 최소 3 개의 연구가 있을 때 수행하였다.

효과크기는 동일 변수에 대해 표준화된 평균차 (standardized mean difference [SMD])를 선택하여 연구 대상자 간의 이질성(heterogeneity)을 고려하여 가중치를 재설정하는 랜덤 효과 모형(random effects model)을 통 해 분석하였대[12]. 선정된 연구들의 동질성은 $\mathrm{I}^{2}$ 과 Cochrane 의 Chi-squared test를 통해 확인하며, $\mathrm{I}^{2}$ 의 결과에서 $40 \%$ 이하일 경우에는 이질성이 낮음을 의미하고 $50 \%$ 에서 $75 \%$ 는 중간을 의미하며 $75 \%$ 이상일 경우에는 높다는 것 을 의미한다[13].

분석된 연구들의 출판 비뚤림(publication bias)은 비대칭 정도를 통계적으로 분석하는 Egger's regression검정을 이 용하여 깔때기 도표(funnel plot)를 분석하여 확인한다[14].

\section{연구 결과}

\section{선정된 무작위 대조시험의 문헌 검색 및 특성}

국외 데이터 베이스를 통해 총 100 개의 연구가 검색되 었다. EndNote X9를 통해 중복된 연구들을 제외하여 58 개의 출판된 문헌들이 선택되었다. 2 명의 연구자는 선정 
및 제외기준에 따라 제목과 초록을 검토하여 48개의 문헌 들을 제외시켰고 선정된 10 개의 문헌이 원문으로 검토되 었다.

검토된 문헌들에서 6 개의 문헌들이 $\mathrm{RCT}$ 가 아니거나 도수치료간 비교한 경우, 연구결과의 누락으로 제외되어 체계적 고찰 및 메타분석이 가능한 연구는 4개로 선정되 었다(Figure 1).

\section{유방암 수술 후 도수치료의 방법론적 질 평가}

질 평가는 2 편의 연구로 연구자간 합의가 필요한 항목 들에 대해 일치율은 $100 \%$ 였다. 4 편의 $\mathrm{RCT}$ 연구에 대한 방법론적 질 평가는 $\mathrm{RoB}$ 를 이용하였고, 7개 항목으로 각 각 무작위 $(+: 3,-: 1)$, 배정순서 은폐 $(+: 2, ?: 2)$, 참가 자 및 연구자의 눈가림(+: $3,-: 1)$, 결과평가자 눈가림 (+: 2, ?: 2), 불완전한 결과자료 $(+: 3,-: 1)$, 선택적 결 과보고(+: 4) 및 기타 비뚤림(+: 4)로 평가하였다(Figure 2).

\section{유방암 수술 후 도수치료}

이 검토에서는 총 133 명의 유방암 수술 후 환자가 포 함된 4 개의 $\mathrm{RCT}$ 가 선정되었다. 각 연구에서는 단독적인 도수치료만이 아닌 추가적인 유형의 중재를 포함시켰다. 통증을 알아보기 위한 평가도구와 팔의 기능을 평가하는 도구가 포함되었다. 선정된 4개의 $\mathrm{RCT}$ 에서는 통증과 팔 기능을 제외한 다른 변수들도 유의한 개선이 나타났으나 일반적인 물리치료 중재가 포함된 대조군도 포함되었다 (Table 1).

\section{통증에 대한 도수치료의 효과}

4개의 RCT에서 133 명의 유방암 수술 환자들이 통증 의 강도에 대해 평가하였다[15-18]. 도수치료를 포함한 일 반적인 물리치료 중재에 해당하는 실험군에서 일반적인 물리치료 중재나 플라시보 치료(placebo therapy)에 해당 하는 대조군들에 대해 유의한 개선이 나타났다. 랜덤 효 과 모형을 통해 분석된 결과는 $\mathrm{SMD}=-0.62 ; 95 \%$ 신뢰 구간(confidence interval [CI]) -0.97 -0.27; heteroneity $(\chi 2=1.37, \mathrm{df}=3, \mathrm{I} 2=0 \%) ; \operatorname{overalleffect}(\mathrm{Z}=3.48)$ 이다 (Figure 3).

\section{팔 기능에 대한 도수치료의 효과}

4 개의 $\mathrm{RCT}$ 에서 133 명의 유방암 수술 환자들이 팔의 기능에 대해 평가하였다[15-18]. 도수치료를 포함한 일반 적인 물리치료 중재에 해당하는 실험군에서 일반적인 물 리치료 중재나 플라시보 치료에 해당하는 대조군들에 대 해 유의한 개선이 나타나지 않았다. 랜덤 효과 모형을 통 해 분석된 결과는 $\mathrm{SMD}=-0.09 ; 95 \%$ CI $-0.43 \sim 0.25$; heteroneity $(\chi 2=0.94, \mathrm{df}=3, \mathrm{I} 2=0 \%)$; over all effect $(Z=0.52)$ 이다(Figure 4$)$.

\section{출판 비뚤림}

출판 비뚤림의 평가는 깔때기 도표(funnel plot)를 통해 검정한 결과에서 시각적인 대칭성을 보여 비뚤림이 없음 을 의미한다고 할 수 있다(Figure 5). 또한, 메타분석에서 다뤄진 연구가 10 개 이하이므로 Egger's regression test 는 실시하지 않았다.

\section{고찰}

본 체계적 고찰 및 메타분석은 유방암 수술 후 통증과 팔의 기능에서 도수치료의 효과를 종합하여 분석하였다. 질적 및 양적분석의 결과에서 도수치료를 시행한 실험군 에서 대조군에 비해 통증에는 유의한 개선이 보였다 $(\mathrm{SMD}=-0.62 ; 95 \% \mathrm{CI}-0.97 \sim-0.25)$. 하지만 팔의 기능에 서는 유의한 개선이 나타나지 않았다(SMD=-0.09; $95 \%$ CI -0.43 0.25).

하지만, 유방암 수술 후 도수치료에 관한 RCT들에서 Cho 등[16]은 일반적인 물리치료와 결합된 도수림프배액 법(manual lymphatic drainage)은 통증조절과 더불어 삶 의 질과 기능모두 향상을 보였다(Cohen's d=0.933, 0.619). 또한, 치료기법에 따른 차이일 수 있으나 근막이 완기법(myofascial release technique)을 통한 관리에서 Groef등 [15]의 연구에서는 통증 조절에 유의한 향상이 있었으나 12 개월까지 장기적으로 유지되지 않았다. Serra-Añó 등[17]의 연구에서는 전반적인 어깨의 움직임 과 기능 및 통증에 대해 유의한 향상이 있었으나 연구의 기간이 다소 짧아 장기적인 영향에 대한 근거로는 부족한 면이 있다. 이외에도 Rangon 등[18]의 연구에서는 허혈 성 압박(ischemic compression)을 통한 치료는 압력 통각 역치(pressure pain threshold)를 증가시켜 결과적으로 유 방암 환자들의 통증 조절에 기여하였다.

유방암 수술 후 환자들의 만성 근골격통증에 대한 도수 치료를 다룬 da Silva 등[19]의 체계적 고찰에서는 만성 통증에 대한 도수치료의 효과에 대해 다루어 통증 경험의 변화를 통한 뇌에 새로운 경험을 생성하는 신경생리학적 접근[20]을 통해 효과에 대한 검증을 하였다. 하지만, 본 고찰에서는 수술 후 환자들이 대상이기에 수술 후 재활의 관점에서 효과를 검증할 수 있다. 수술 후 통증은 급성 통 증으로 분류되며[21], 도수치료의 포괄적인 접근[22]을 통 해 급성 통증의 조절에 미치는 자율신경계 반응[23-25]과 신경근 반응[26]을 통한 진통효과[27]로 여겨진다. 또한, 선정된 연구들에서 각 도수치료 기법들의 치료원리로는 수술 후 조직의 유착을 제거하기 위해 주로 사용되는 기 법들로 구성되어 효과적인 통증조절에 기여했다고 여겨진 다[15-17]. 


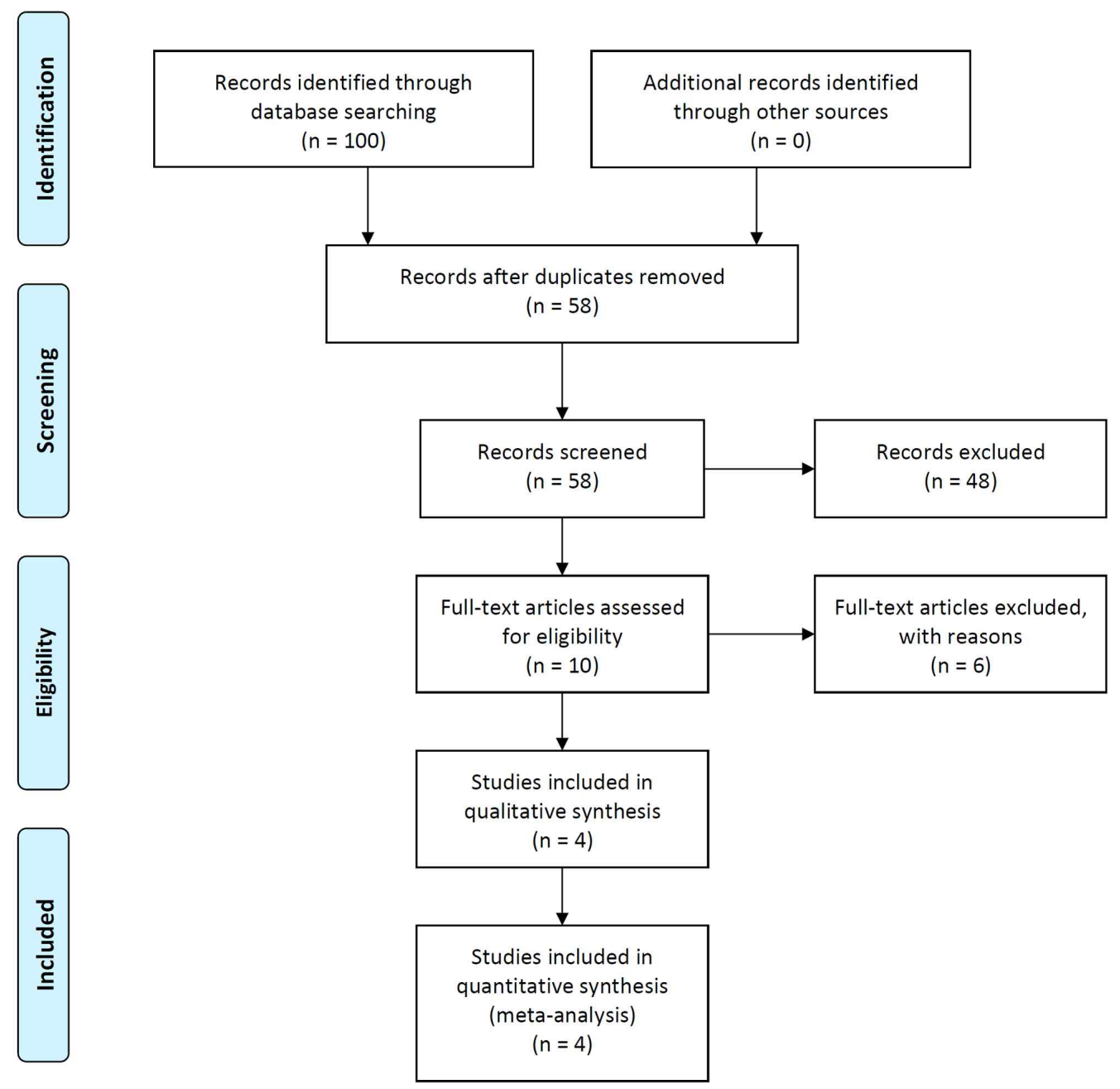

Figures 1. PRISMA flow diagram

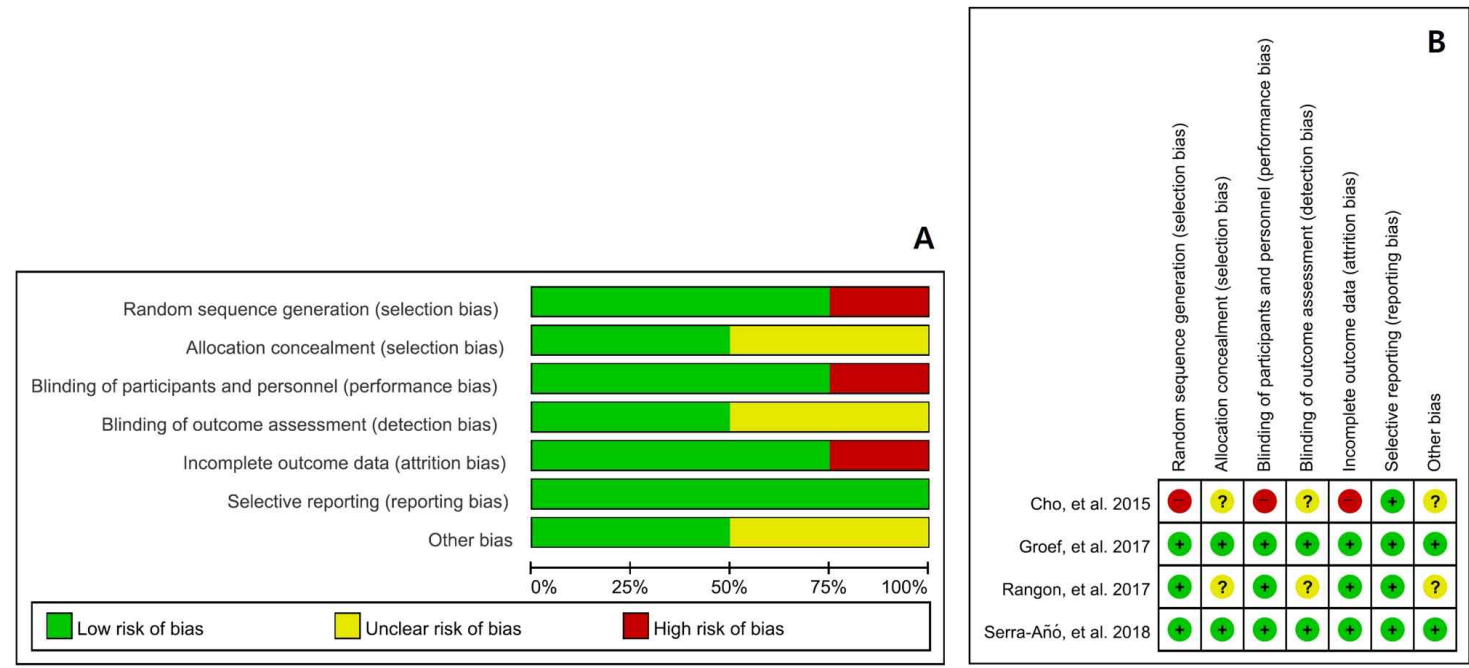

Figure 2. Risk of bias of the systematic review. (A) Risk of bias graph: review authors' judgements about each risk of bias item presented as percentages across all included studies, (B) risk of bias summary: review authors' judgements about each risk of bias item for each included study. 


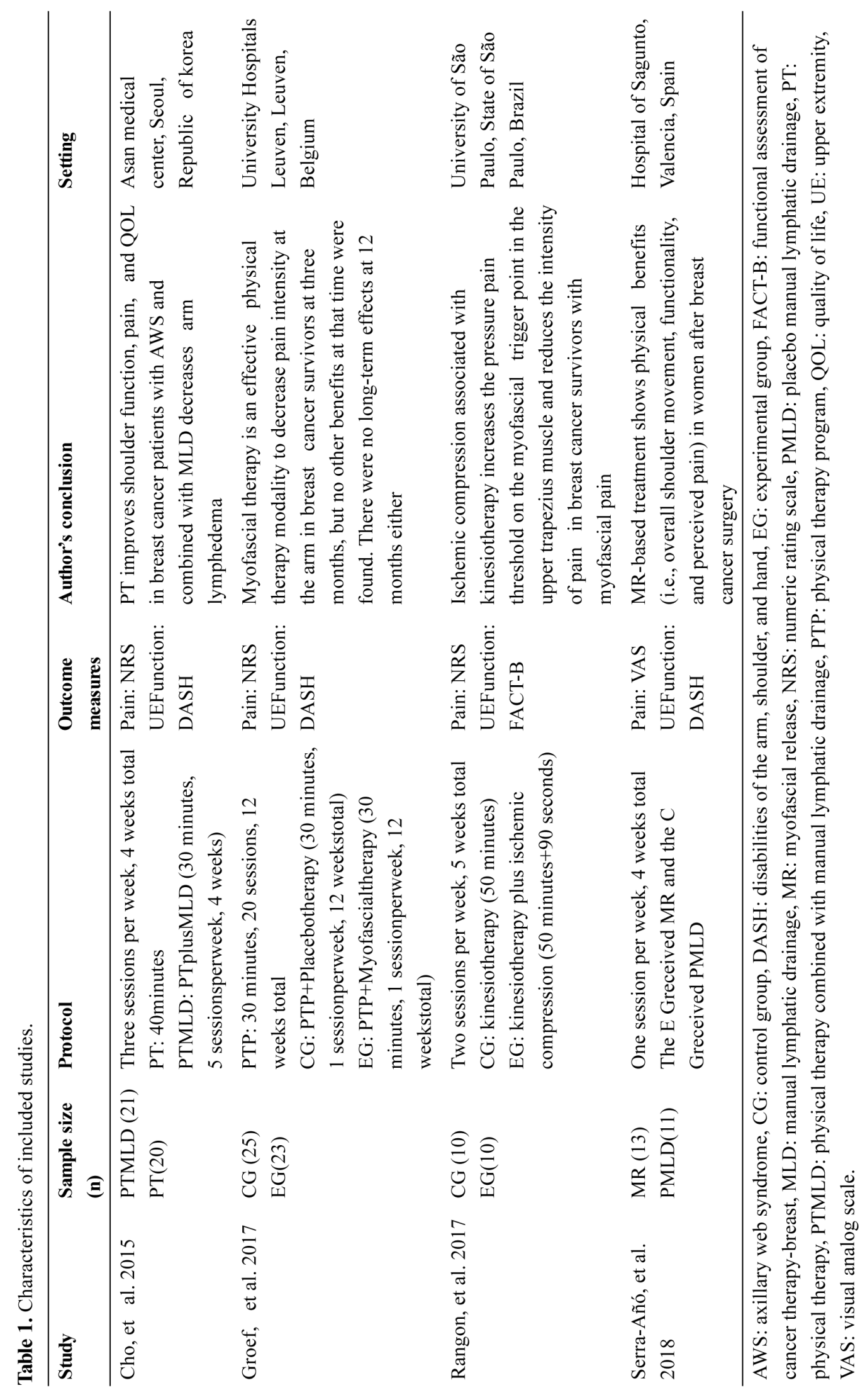




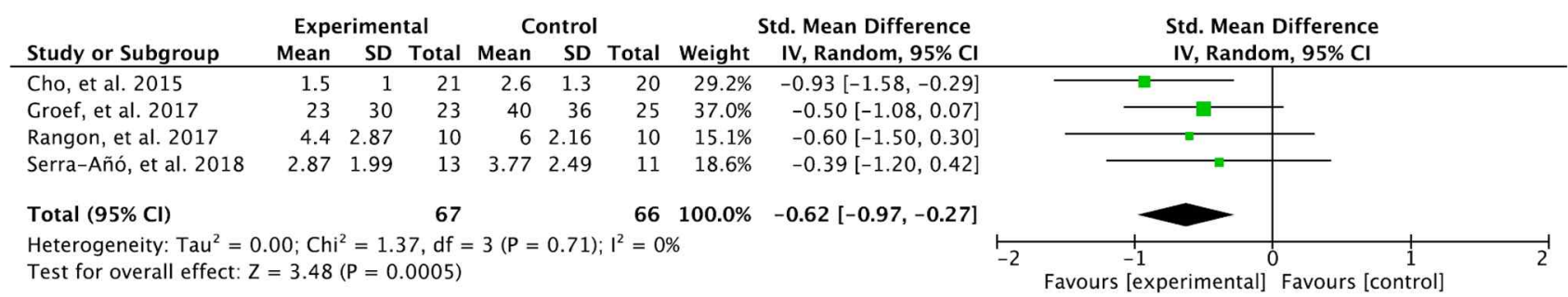

Figure 3. Forest plot on the effect of manual therapy on pain.

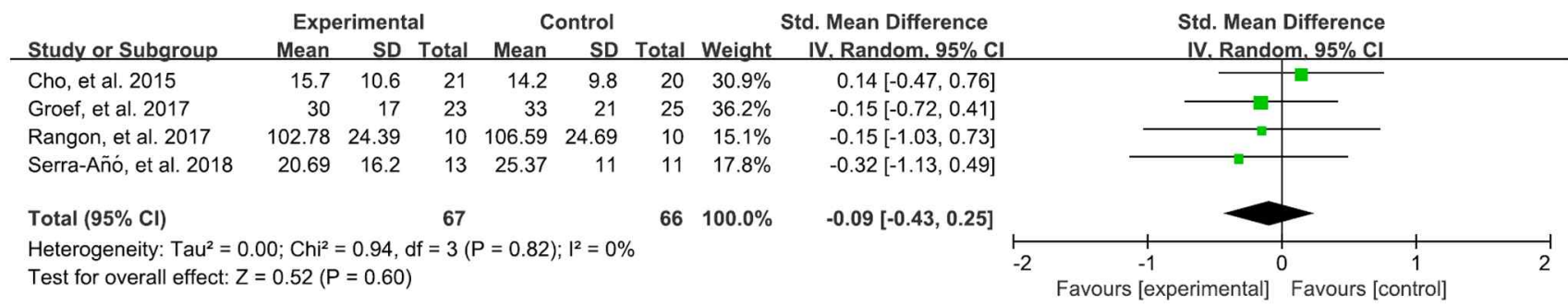

Figure 4. Forest plot on the effect of manual therapy on upper extremity function.
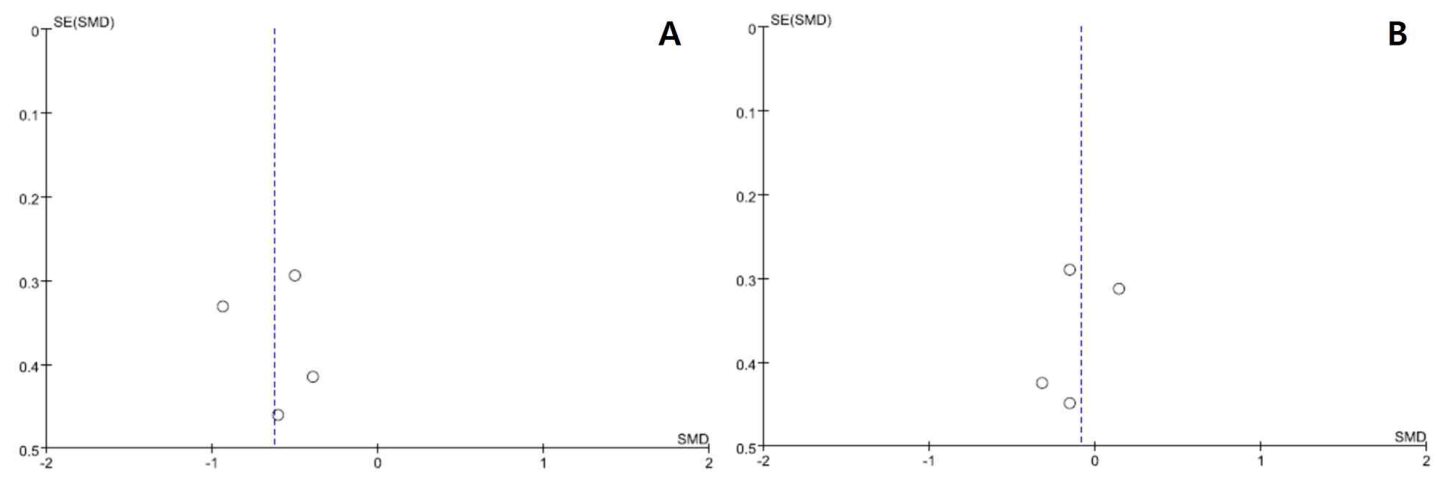

Figure 5. Funnel plot supports low risk of publication bias. (A) pain, (B) upper extremity function.

본 검토에서 선정된 연구들에서 팔의 기능은 실험군이 대조군에 비해 유의한 개선이 없다는 것으로 나타났다. 하지만, Cho 등[16]의 연구에서 일반적인 물리치료를 수 행한 대조군은 실험 전과 후를 Cohen's d를 통해 비교하 였을 때, 큰 효과크기를 나타냈다 $(\mathrm{d}=0.806)$. 또한, Groef 등[15]과 Rangon 등[18]에서는 작은 효과크기 $(\mathrm{d}=0.264$, $\mathrm{d}=0.349)$, Serra-Añó 등[17]에서는 중간 효과크기 $(\mathrm{d}=$ 0.736)를 보였다. 이러한 결과는 일반적인 물리치료나 치 료행위가 포함된 대조군과 비교하였을 때에는 팔의 기능 에 유의한 차이는 없었지만 기능의 향상에는 기여한다는 것으로 해석할 수 있다.

유방암 수술 후 통증과 팔의 기능에 대한 도수치료의 효과를 알아보기 위해 다양한 도수치료의 기법, 방법, 강 도 등에 대해 더욱 많은 이해가 필요하다. 또한, 본 고찰 에서는 유방암 수술 후 도수치료 중재가 끝나는 평가시점
의 결과자료로 제시되었기 때문에 시기에 따른 증상으로 는 분류가 이루어지지 않아 장기 추적관찰에 대해 다루지 않았다. 따라서, 추후 체계적 고찰 또는 RCT에서는 도수 치료 기법에 따른 분류, 수술 전 중재, 수술 후 만성 통증 에 대한중재가 요구되며, 도수치료 후 추적관찰 시기를 포함하여 장기적인 환자관리에 미치는 잔존 효과에 대해 다룰 필요가 있다.

\section{결론}

본 체계적 고찰 및 메타분석에서는 유방암 수술 후 관 리에 있어 도수치료의 효과에 대한 임상적 제언을 위해 수행되었다. 현재 증거는 유방암 수술 후 팔의 통증을 호 소하는 환자들에게 도수치료가 통증 조절에 효과적이라는 것을 보여준다. 


\section{감사의 글}

본 연구는 2021년(2021010) 광주보건대학교 연구지원 금으로 진행되었습니다.

\section{이해 충돌}

본 연구의 저자들은 연구, 저자권, 및 출판과 관련하여 잠재적인 이해충돌이 없음을 선언합니다.

\section{참고문헌}

1. Lee PLT, Tam K-W, Yeh M-L, Wu W-W. Acupoint stimulation, massage therapy and expressive writing for breast cancer: a systematic review and meta-analysis of randomized controlled trials. Complement Ther Med. 2016;27:87-101.

2. Eyigor S, Uslu R, Apaydın S, Caramat I, Yesil H. Can yoga have any effect on shoulder and arm pain and quality of life in patients with breast cancer? A randomized, controlled, single-blind trial. Complement Ther Clin Pract. 2018;32:40-5.

3. Stubblefield MD, Custodio CM. Upper-extremity pain disorders in breast cancer. Arch Phys Med Rehabil. 2006;87:96-9.

4. Runowicz CD, Leach CR, Henry NL, Henry KS, Mackey HT, Cowens-Alvarado RL, et al. American cancer society/American society of clinical oncology breast cancer survivorship care guideline. CA Cancer J Clin. 2016;66:43-73.

5. FERNÁNDEZ-LAO C, CANTARERO-VILLANUEVA I, DÍAZ-RODRÍGUEZ L, Cuesta-Vargas A, FERNÁNDEZDELAS-PEÑAS C, ARROYO-MORALES M. Attitudes towards massage modify effects of manual therapy in breast cancer survivors: a randomised clinical trial with crossover design. Eur $\mathrm{J}$ Cancer Care. 2012;21:233-41.

6. Vernon H, Humphreys B. Manual therapy for neck pain: an overview of randomized clinical trias and systematic reviews. Europa Medicophysica. 2007;43:91.

7. Wisotzky E, Hanrahan N, Lione TP, Maltser S. Deconstructing postmastectomy syndrome: implications for physiatric management. Phys Med Rehabil Clin N Am. 2017;28:153-69.

8. De Groef A, Van Kampen M, Dieltjens E,
Christiaens M-R, Neven P, Geraerts I, et al. Effectiveness of postoperative physical therapy for upper-limb impairments after breast cancer treatment: a systematic review. Arch Phys Med Rehabil. 2015;96:1140-53.

9. Basilio FB, Dos Anjos RdMM, De Medeiros EP, De Melo EMF, da Silva RMV. Effects of manual therapy techniques in the treatment of pain in post mastectomy patients: systematic review. Man Ther Posturol Rehabil J. 2014:1-6.

10. Kim MH, Lee KY, Park S, Kim SI, Park HS, Yoo YC. Effects of systemic lidocaine versus magnesium administration on postoperative functional recovery and chronic pain in patients undergoing breast cancer surgery: a prospective, randomized, double-blind, comparative clinical trial. PloS one. 2017;12:e173026.

11. Teguh DN, Raap RB, Struikmans H, Verhoef C, Koppert LB, Koole A, et al. Hyperbaric oxygen therapy for late radiation-induced tissue toxicity: prospectively patient-reported outcome measures in breast cancer patients. Radiat Oncol. 2016;11:1-6.

12. Riley RD, Higgins JP, Deeks JJ. Interpretation of random effects meta-analyses. BMJ. 2011;342:d549.

13. Green S, Higgins JP. Cochrane handbook for systematic reviews of interventions version 5.1.0. Cochrane Collaboration; 2011.

14. Duval S, Tweedie R. Trim and fill: a simple funnelplot-based method of testing and adjusting for publication bias in meta-analysis. Biometrics. 2000;56:455-63.

15. De Groef A, Van Kampen M, Vervloesem N, Dieltjens E, Christiaens M-R, Neven P, et al. Effect of myofascial techniques for treatment of persistent arm pain after breast cancer treatment: randomized controlled trial. Clin Rehabil. 2018;32:451-61.

16. Cho Y, Do J, Jung S, Kwon O, Jeon JY. Effects of a physical therapy program combined with manual lymphatic drainage on shoulder function, quality of life, lymphedema incidence, and pain in breast cancer patients with axillary web syndrome following axillary dissection. Support Care Cancer. 2016;24: 2047-57.

17. Serra-Añó $P$, Inglés $M$, Bou-Catalá $C$, Iraola-Lliso A, Espí-López GV. Effectiveness of myofascial release after breast cancer surgery in women under- 
going conservative surgery and radiotherapy: a randomized controlled trial. Support Care Cancer. 2019;27:2633-41.

18. Rangon FB, Ferreira VTK, Rezende MS, Apolinário A, Ferro AP, de Oliveira Guirro EC. Ischemic compression and kinesiotherapy on chronic myofascial pain in breast cancer survivors. J Bodyw Mov Ther. 2018;22:69-75.

19. da Silva FP, Moreira GM, Zomkowski K, de Noronha MA, Sperandio FF. Manual therapy as treatment for chronic musculoskeletal pain in female breast cancer survivors: a systematic review and meta-analysis. J Manipulative Physiol Ther. 2019;42:503-13.

20. Nijs J, Girbés EL, Lundberg M, Malfliet A, Sterling M. Exercise therapy for chronic musculoskeletal pain: innovation by altering pain memories. Man Ther. 2015;20:216-20.

21. Kehlet H. Acute pain control and accelerated postoperative surgical recovery. Surg Clin North Am. 1999;79:431-43.

22. Bialosky JE, Bishop MD, Price DD, Robinson ME, George SZJMt. The mechanisms of manual therapy in the treatment of musculoskeletal pain: a comprehensive model. Man Ther. 2009;14:531-8.

23. Lanotte M, Lopiano L, Torre E, Bergamasco B, Colloca L, Benedetti F. Expectation enhances autonomic responses to stimulation of the human subthalamic limbic region. Brain Behav Immun. 2005;19:500-9.

24. Pollo A, Vighetti S, Rainero I, Benedetti F. Placebo analgesia and the heart. Pain. 2003;102:125-33.

25. Johansen O, Brox J, Flaten MA. Placebo and nocebo responses, cortisol, and circulating beta-endorphin. Psychosom Med. 2003;65:786-90.

26. Goffaux P, Redmond WJ, Rainville P, Marchand S. Descending analgesia-when the spine echoes what the brain expects. Pain. 2007;130:137-43.

27. Price DD, Staud R, Robinson ME, Mauderli AP, Cannon R, Vierck CJ. Enhanced temporal summation of second pain and its central modulation in fibromyalgia patients. Pain. 2002;99:49-59. 